Sabah A Ismail

BDS, MSc (Asst. Prof.)

Wiaam M O Al-Ashou

BDS, MSc (Asst. Lec.)

Raghad A Al-Askary BDS, MSc (Lec.)

\section{Evaluation of the Apical Seal in Root Canals Prepared with Rotary ProTaper Files and Obturated by Different Meth- ods}

\author{
Department of Conservative Dentistry \\ College of Dentistry, University of Mosul
}

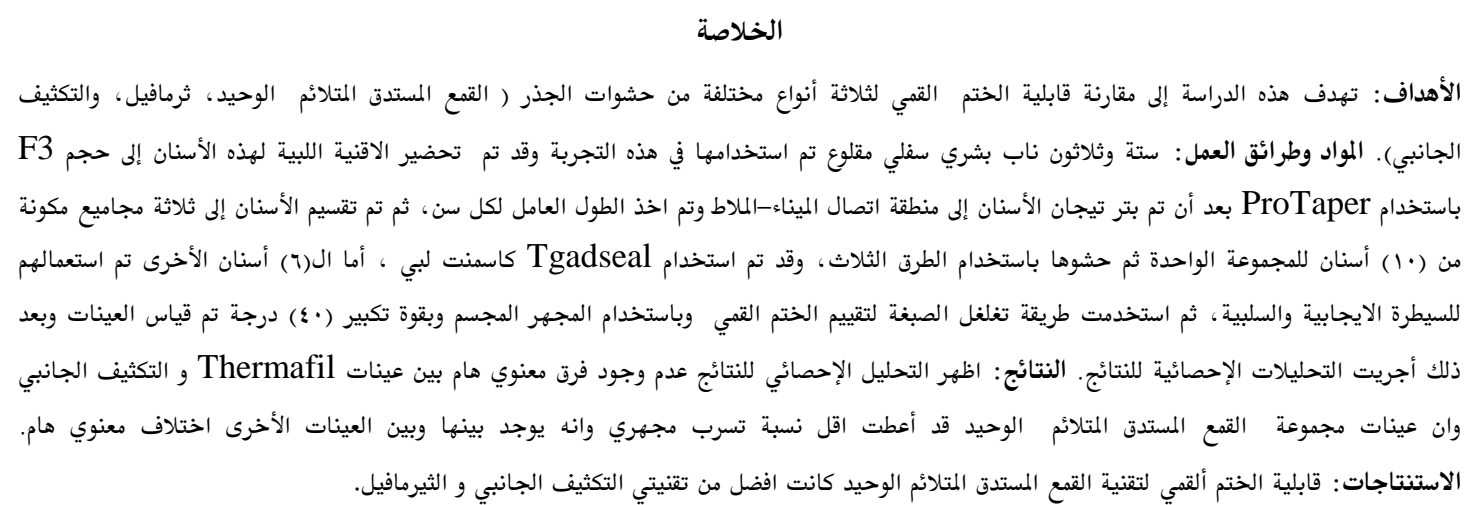

Abstract

Aims: The aim of this in vitro study was to evaluate the apical sealing ability of matched-taper Singlecone, Thermafil, and Cold lateral condensation obturations. Materials and Methods: Thirty-six extracted human lower canine teeth were instrumented to size (F3) with ProTaper rotary instruments after cutting of their crowns to the cement-enamel junction CEJ. The working length was determined for each tooth. The teeth were divided into (3) groups (10) of each and (6) teeth were used as a positive and negative control groups. The teeth were obturated with matched-taper Single-cone, Thermafil, and lateral condensation techniques. Tgadseal was used as a root sealer in this study. A die penetration method was used to evaluate the apical seal using a stereomicroscope at 40X magnification. One-way analysis of variance and Duncan's tests were used for statistical analysis. Results: The statistical analysis of the results demonstrated that there was no statistically significant difference in microleakage between the lateral condensation and Thermafil groups. The matched taper single cone showed the least microleakage with a significant difference than the other two groups. Conclusions: The apical sealing ability of Matched-taper Single-cone obturation was better than the lateral condensation and Thermafil techniques when the root canal was prepared using a ProTaper rotary instrumentation.

Key words: Apical seal, Rotary ProTaper files, Root canal obturation, Thermafil, Lateral condensation.

Ismail SA. Al-Ashou WM. Al-Askary RA. Evaluation of the Apical Seal in Root Canals Prepared with Rotary ProTaper Files and Obturated by Different Methods. Al-Rafidain Dent J. 2011; 11(2): 390 $-396$.

Received: 1/6/2010 Sent to Referees 3/6/2010

Accepted for Publication: 5/10/2010

\section{INTRODUCTION}

The three dimensional obturation of the root canal system is widely accepted as a key factor for successful endodontic therapy. A three dimensional well fitted root canal prevents percolation and micro leakage of periapical exudates into the root canal space, prevents re-infection, and cre- ates a favorable biological environment for healing to take place. ${ }^{(1)}$

Gutta-percha is the most commonly used root canal obturation material. Its physical properties have made possible several different obturation techniques. The Cold lateral condensation is one of the 
most commonly used techniques in endodontics. However, its ability to replicate the internal surface of the root canal has been questioned. Voids, spreader vertical tracts, incomplete fusion of gutta-percha cones, and lack of surface adaptation have been reported. ${ }^{(2)}$

Johnson introduced a technique in which alpha phase gutta-percha was placed on a metal carrier, heated and used to obtuurate the root canal. This system is commercially available as thermafil endodontic obturators. ${ }^{(1,3)}$

The introduction of nickel titanium rotary instrumentation has made endodontics easier and faster than hand instrumentation, resulting in consistence and predictable root canal shaping. The rotary technique less fatiguing for the practitioner and nickel titanium decreases postoperative pain for the patient, most likely due to the combination of file design and crown down modality. ${ }^{(4,5,6)}$

Recently, new file designs of rotary NiTi instruments with sharp cutting edges called ProTaper were introduced. They are especially designed to provide superior flexibility, efficiency and safety since they have convex triangular cross-sectional design, a non-cutting safety tip, and an advanced flute design that combines multiple tapers within the shaft. ${ }^{(7,8)}$

Because of the widespread use of rotary nickel titanium systems, manufacturers have produced gutta percha cones that match the taper of the canals prepared with these systems. ${ }^{(4,7)}$

Recently, gutta-perch points for ProTaper system have been introduced for simple, time-efficient obturation. In this system, root canal is prepared with ProTaper instruments and filled with the point that fits the size of the finisher file, the manufacturer claims that ProTaper gutta-perch points perfectly fit canals that have been prepared with ProTaper file. ${ }^{(7)}$

The aim of this study is to compare the apical sealing ability of matched-taper single cone, Thermafil and lateral condensation techniques in teeth prepared with ProTaper rotary instrument.

MATERIALS AND METHODS

Thirty six lower canine human teeth with mature apices extracted for periodontal and prosthetic reasons were used. The teeth were cleaned and polished, and then the crowns were removed at cementoenamel junction with diamond wheel saw (KG Sorensen SP, Brazil) under water coolant. The roots were accessed and to determine the working length, a size \# 15 $\mathrm{k}$ - file (MANI, INC. JAPAN ) was inserted into the canal until it was visible at the apical foramen. The working length of each canal was calculated to be $1 \mathrm{~mm}$ short of that position (from the apical foramen).

All teeth were prepared with ProTaper NiTi rotary instruments to size F3. A total of 6 instruments were used with contraangle rotary hand piece (Endo-Mate DT, NSK NAKANISHI, INC., JAPAN). The speed of rotation was maintained at 250 rpm and torque $3 \mathrm{Nm}$. Glyde (Dentsply /Maillefer; Tulsa, Okla.) was used as a lubricant during instrumentation. Two milliliters of $2.5 \%$ sodium hypochlorite solution were used for irrigation between each file size. ProTaper files were used in the following sequence, according to the manufacturer's recommendations:

1. The pulp chamber was filled with Glyde for lubrication and the S1 file was used to enlarge the coronal two-thirds of the canal.

2. The canal was irrigated using two milliliters of $2.5 \%$ sodium hypochlorite solution and the SX file was inserted into the canal until it encountered light resistance. Shaping with the SX was continued with a brushing motion until twothirds of its cutting blades were below the orifice.

3. The canal was irrigated and a size \# $10 \mathrm{~K}$-file was used for recapitulation.

4. Shaping continued with the S1 file to the working length.

5. Then the S2 file was taken to the working length.

6. The F1 file was taken to the full working length and immediately withdrawn.

7. The F2 file was taken to the full working length and immediately withdrawn.

8. The F3 file was taken to the full working length and immediately withdrawn. 
After the preparation procedure was complete, the teeth were irrigated with sodium hypochlorite, then randomly divided into 3 groups, each consist of 10 samples. The remaining 6 teeth were used as positive and negative controls. Tgadseal root canal sealer (Technical \& General LTD. London-United Kindom) was used as a sealer and the root canals were obturated as follows:

Group I: Obturated using Matchedtaper Single-cone (gutta-percha for ProTaper, size F3) technique .

Group II: Obturated using Cold lateral condensation technique.

Group III: Obturated using the Thermafil technique.

Matched-taper Single Cone Obturation

A size F3 gutta- percha ( Dentsply Maillefer) was pre-fitted into the root canal at the working length. The canal was dried with paper point and sealer was applied to the root canal walls with size \# 30 k-file. The cone was lightly coated with Tgadseal root canal sealer and placed into the canal to the working length. The excess gutta-percha was removed with heated instrument and the canal orifice was sealed with Tetric ceram composite resin(ivoclar vivadent AG, FL- 9494 Schaan/ Liechtenstein).

\section{Cold lateral Condensation Obturation}

A size 30 gutta-percha cone ( DiaDent Eurpe B.V. Almere, Netherlands, KOREA) was pre-fitted into the canal at the working length. The canal was dried with paper point and Tgadseal was applied to the root canal walls with size \# 30 $\mathrm{k}$-file. The master cone was placed into the canal at the working length. Lateral condensation was done with accessory cones and spreader. Lateral condensation was completed when the spreader could no longer penetrate into the canal. Excess gutta-percha was then removed with a heated instrument and access cavities was sealed with Tetric ceram composite resin. Thermafil Obturation

A size \#30 ( Gamma irradiated, DK under US patent No. 5,588,,835) verifier was pre-fitted into the canal at the working length. The same size Thermafil obturator was heated in the Soft-Core ${ }^{\circledR}$ DT oven (CMS Dental. 21G Njalsgade DK-2300 Copenhagens). The canal was dried, and
Tgadseal was applied to the root canal wall with size \# 30 reamer. Then the obturator was slowly placed at the working length in a single motion. After the guttapercha was cooled, the obturator was severed at the canal orifice and the canal was sealed with Tetric ceram composite resin.

After obturation, all teeth were incubated at $37 \mathrm{C} \dot{\circ}, 100 \%$ humidity, for 7 days to allow the sealing materials to set fully. In the experimental groups, all root surfaces except the apical $2 \mathrm{~mm}$ were covered with two coats of nail polish.

The root canals were not obturated in the positive control group to allow $100 \%$ leakage. The root surfaces of these teeth were also coated with 2 layers of nail polish, except the apical $2 \mathrm{~mm}$. The teeth in the negative control group were obturated with lateral condensation, singlecone or Thermafil techniques, and all root surfaces were covered with two layers of nail polish to ensure that there was no leakage.

The experimental and control groups were each placed in numbered containers which were filled to identical levels with $2 \%$ methylene blue dye for three days. The teeth were rinsed with running water and dried.

The tooth roots were grooved buccally and lingually with a diamond wheel saw (KG Sorensen SP, Brazil) under water coolant, ensuring that the root canal filling was not penetrated, and then they were split into two halves by levering with a plaster knife. The linear extent of dye penetration from the apical root ends was measured using a stereomicroscope (Motic, TAIWAN) at (X 40 magnification) by two observers in millimeters. The data were statistically analyzed using one-way ANOVA ( $p \leq 0.05)$, and Duncan's testes to determine statistically significant differences between groups.

\section{RESULTS}

The positive control teeth showed complete dye penetration where as the negative control teeth showed no dye leakage.

The result of one way ANOVA test ( table 1, Figure 1) revealed that there was 
a significant difference among the groups

$$
(p \leq 0.05)
$$

Table (1): One Way ANOVA Tests For The Apical Microleakage Among The Experimental Groups.

\begin{tabular}{cccccc}
\hline & $\begin{array}{c}\text { Degree of } \\
\text { freedom }\end{array}$ & $\begin{array}{c}\text { Sum of } \\
\text { squares }\end{array}$ & Mean square & F & Sig. \\
\hline Between groups & 2 & 1.726 & 0.863 & 4.866 & 0.018 \\
Within groups & 27 & 3.726 & 0.177 & & \\
Total & 29 & 5.450 & & & \\
\hline
\end{tabular}

Sig.: Significant at $(p \leq 0.05)$

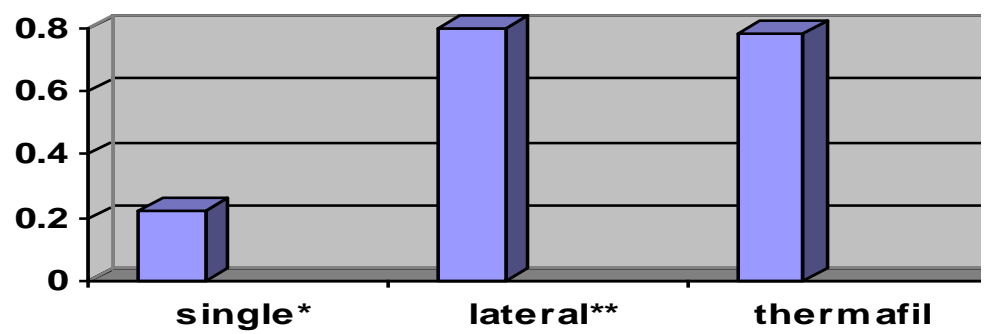

Figure (1): The Effect Of Different Obturation Methods On Apical Microleakage.

$*=$ Single Cone $\quad * *=$ Lateral Condensation

Duncan's multiple rang test (Table 2) showed that group I (Matched-taper Single cone obturation) represent the lowest mean of dye penetration $(0.22 \pm 0.23 \mathrm{~mm})$, and the difference was statistically significant from the other groups, and although group
II (lateral condensation) showed more leakage mean $(0.80 \pm 0.50 \mathrm{~mm})$ than group III (Thermafil) $(0.78 \pm 0.46 \mathrm{~mm})$, but the difference between the two groups was not significant as shown in Figure (2).

Table (2): Duncan's Multiple Range Tests For The Experimental Groups

\begin{tabular}{cccc} 
Group & $\begin{array}{c}\text { Mean leakage } \\
(\mathbf{m m})\end{array}$ & $\begin{array}{c}\text { Standard } \\
\text { deviation }\end{array}$ & Duncan's group \\
\hline Matched-taper Single cone & 0.22 & 0.23 & $\mathrm{~A}^{*}$ \\
Lateral condensation & 0.80 & 0.50 & $\mathrm{~B}$ \\
Thermafil & 0.78 & 0.41 & $\mathrm{~B}$ \\
\hline * & &
\end{tabular}

\footnotetext{
* Different letters mean significant differences.
} 

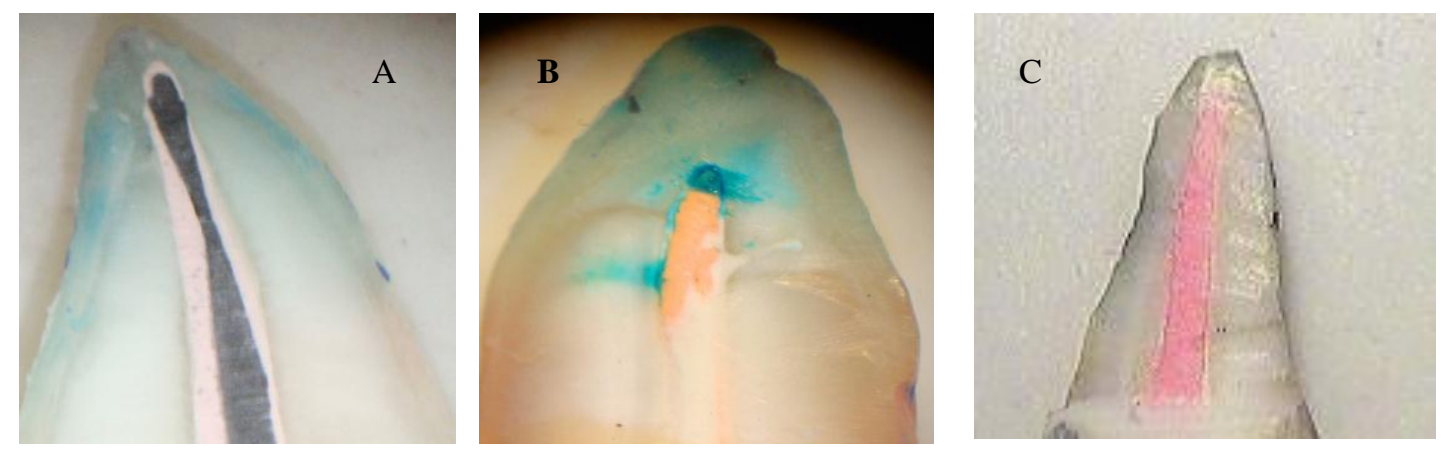

Figure (2) : Microleakage of Different Obturating Technique. (A ) Thermafil (B) Cold Lateral Condensation (C) Matched-Taper Single Cone.

\section{DISCUSSION}

The root canal is a complex system with many surface irregularities, fins, accessory and lateral canal, and isthmuses. To seal this system, the filling material must adapt to all portions of the root canal. Incomplete obturation of the canal system may result in failure of the endodontic treatment. Root canal filling materials are intended to prevent microorganisms and toxins in the canal from passing along the root canal space into periradicular tissues. ${ }^{(9)}$

This study evaluated the ability of a three obturation methods (Single-cone, Cold lateral, and Thermafil) to seal root canals prepared with the ProTaper NiTi rotary instruments using methylene blue dye penetration methods.

Under the condition of this in vitro study leakage in Cold lateral condensation group show the highest mean $(0.80 \pm 0.50) \mathrm{mm}$ which was followed by Thermafil group $(0.78 \pm 0.46) \mathrm{mm}$, while the single cone group show the lowest mean $(0.22 \pm 0.23)$ of leakage.

The positive control group showed dye penetration into the canals and dentinal tubules of the teeth, whereas the negative control group did not demonstrate dye penetration indicating that the leakage model chosen was appropriate for the purpose of the present study.

Resin sealer (tgadseal) was chosen in this study because of its low solubility in comparison with other sealer like silicone, $\mathrm{Ca}(\mathrm{OH}) 2$, zinc-oxide eugenol, and glass ionome GI based sealers. ${ }^{(10,11)}$

Lateral condensation technique has shown to form a non-homogenous mass of gutta-percha that poorly replicates the prepared root-canal space and does not adequately obturate simulated lateral canals. Additionally, lateral compaction technique leaves voids between cones that often are not filled with sealer and may provide a niche for bacteria to thrive. ${ }^{(9,10)}$ This may possibly explain the fact that the root canals obturated with this technique numerically presented the highest mean apical infiltration.

Although the aim of lateral condensation is to fill the space surrounding the master cone with gutta-percha by the use of accessory points, but an accessory point was rarely observed in cross-sections of the apical third. ${ }^{(12,13)}$

Thermafil technique permitted the flow of gutta-percha into unprepared recesses of the canal. ${ }^{(2,12)}$

The superior sealing ability of Thermafil can be attributed to its ability in filling main canal as well as lateral canals. The plastic carrier in Thermafil system could also act as plunger, which effectively forces the thermoplasticized guttapercha into the lateral walls of the canal, it was also found that there were fewer voids in the apical third of the obturation when compared to that of lateral condensation. ${ }^{(1,14)}$

In this study there was no significant difference between lateral condensation and Thermafil groups. Although lateral 
condensation group show the more leakage than Thermafil.

A number of studies evaluated the Thermafil obdurators and found that it proved a better seal than lateral condensation. ${ }^{(1,3,13,14)}$

Inan and colleagues ${ }^{(3)}$, reveal that Thermafil groups show significantly less microleakage than Cold lateral condensation groups in both electrochemical and dye penetration evaluations.

The Single-cone technique consists of a single gutta-perch cone filled at room temperature with sealer layer thicknesses that vary, depending on the adaptation of single cone to the walls of the canals. ${ }^{(7)}$

The single cone technique using a ProTaper matching gutta-percha point that is simpler and faster than other obturation techniques was acceptable for filling canals, especially at the apical third. ${ }^{(12)}$

in this study single cone group show significantly less leakage than the Thermafil and Cold lateral condensation groups.

Zmener and colleagues ${ }^{(15)}$ reported that with the use of a methacrylate-based sealer, the difference between Single-cone and Cold lateral condensation obturation was not significant.

Mokhles $^{(16)}$, also show no statistically significant differences between Cold lateral condensation and Single-cone groups.

Inan and colleagues ${ }^{(7)}$, in another research show that there was no significant differences among ( Single-cone, Thermafil, and Cold lateral condensation) groups in microleakage. Although the lateral condensation group showed more leakage than the other groups.

\section{CONCLUSIONS}

Under the limitation of this study, the results indicated that, a combination of ProTaper rotary instrumentation with Single-cone obturation showed less microleakage in terms of linear dye penetration. There were no significant differences between the Thermafil and the lateral condensation obturation technique. Although, the Thermafil group showed microleakage less than that in Cold lateral condensation group.

\section{REFERENCES}

1. Rajeswari P, Gopikrishan V, Parameswaran A, Gupta T, Kandaswamy D. In-vitro evaluation of apical microleakage of Thermafil and Obtura II heated gutta percha in comparison with Cold lateralcondensation using fluid filtration system. Endodontology; 2007: 1924-31.

2. Weller RN, Kimbrough W, Ronald W. A comparison of thermoplastic obturation techniques: adaptation to the canal walls. J Endod. 1997; 23: 703-706.

3. Inan $\mathrm{U}$, Aydemir $\mathrm{H}$, Taşdemir $\mathrm{T}$. Leakage evaluation of three different root canal obturation technique using electrochemical evaluation and dye penetration method. Aust Soc Endod J. 2007; 33: 18-22.

4. 4-Subhy A, Mhammed R. A comparative study of the sealing ability of two different obturation techniques with and without the use of sealers. $J$ Baghad 2008; 20: 5-7.

5. Dayal C, Sajjan G, Subhash T An in Vitro Evaluation of Microhardness of Root Dentin Prepared With Different File Types with $2.5 \%$ Sodium Hypochlorite. Endodontology. 2007; 19: 2329.

6. Walton R and Torabinejad M. Endodontic instrument. Principles and practice of endodontic. 2002; Ch 10, Saunders.

7. Inan U, Aydin C, Tunca Y, Basak F. In vitro evaluation of matched-taper single-cone obturation with fluid filtration method. JADA. 2009; 75: 123123.

8. Glickman $G$ and Koch K. 21 Stcentury endodontic. JADA. 2000; 131: 39-46.

9. Kandaswamy D, Venkateshbaba N, Reddy G, Hannah R, Arathi G, Roohi R. Comparison of laterally condensed, vertically compacted thermoplasticized, cold free-flow GP obturationsA volumetric analysis using spiral CT. J Conserve Dent. 2009; 12(4): 145149.

10. Brosco VH, Bernardineli N, Moraes IG. "In vitro" evaluation of the apical sealing of root canals obturated with different techniques. J Appl Oral Sci. 2003; 11(3). 
11. Schäfer E, and Zandbiglari T. Solubility of root canal sealers in water and artificial saliva. Int Endod J. 2003; 36(10): 660-9.

12. Ozawa T, Taha N, Messer H. A comparison of techniques for obturating oval-shaped root canals. Dent Mate J.2009; 28(3): 290-249.

13. Gençoğlu N, Garip Y, Baş M, Samani S. Comparison of different guttapercha root filling techniques: Thermafil, Quick-fill, System B, and lateral condensation. Oral Surg Oral Med Oral Pathol Oral Radiol Endod. 2002; 93(3): 333-6.

14. Kirk DA, Christen NJ, Terry TJ, Patrick FJ, Fjohn H. Comparison of the obturation of lateral canals by six techniques. J Endod. 1999; 25: 376380.

15. Zmener O, Pameijer $\mathrm{CH}$, Macri E. Evaluation of the apical seal in root canals prepared with a new rotary system and obturated with a methacrylate based endodontic sealer: an in vitro study. J Endod. 2005; 31(5): 392-5.

16. Mokhless N. Evaluation of the apical sealing ability of matched taper singlecone and Cold lateralcondensation techniques after irradiation with 980nm diode laser. Dent Assoc J. 2009; 55(2): 1445. 